\title{
SYSTEMATIZED EPIDERMOLYTIC EPIDERMAL NEVUS (ICHTHYOSIS HYSTRIX)
}

\author{
Sonya Márina, Kristina Semkova, Jana Kazandjieva, Dimitrina Guleva \\ Department of Dermatology and Venereology, Medical University of Sofia
}

\begin{abstract}
Ichthyosis hystrix is a term used to describe an autosomal dominant rare form of an ichthyosiform dermatosis which is characterized by hyperkeratotic spiny scales. We present a healthy 22 -year-old man with lesions which clinically and histopathologically corresponded to the rare inherited disorder ichthyosis hystrix.
\end{abstract}

Keywords: systematized epidermal nevus, congenital hamartomas, epidermolytic hyperkeratosis

\section{INTRODUCTION}

Systematized epidermal nevus, sometimes also referred to as Ichthyosis hystrix (IH), is a rare form of organoid nevi presenting clinically as diffuse, hyperkeratotic plaques involving extensive areas of the body. It is currently considered a mosaic form of congenital bullous ichthyosiform erythroderma (BIE). Histological examination is therefore indispensable to identify the risk for the offspring. When found in these lesions, epidermolytic hyperkeratosis (EHK) is an alarming feature and should prompt relevant genetic counseling. Treatment of IH and epidermal nevi in general is usually symptomatic. The main therapeutic target is hyperkeratosis reduction. Systemic or topical retinoids may be beneficial, as well as topical formulations of urea or salicylic acid.

\footnotetext{
Address for correspondence:

Dimitrina Guleva

Department of Dermatology and Venereology

Medical University-Sofia

1 G. Sofiiski blvd.

1431, Sofia, Bulgaria

e-mail:dimiguleva@gmail.com
}

Received: August 2, 2015

Accepted: September 28, 2015

\section{MATERIAL AND METHODS}

A 22-year old male presented to our clinic with a long-term history of warty plaques affecting the trunk and extremities. The lesions were first noted at the age of two months as slightly erythematous and scaly patches that gradually thickened and got covered by thick, white spiny scales. Blisters never formed within the lesion. The family history was unremarkable, with no epidermal nevi in both parents. Physical examination revealed extensive hyperkeratotic, hyperpigmented plaques in a Blaschkoid distribution affecting the trunk, neck, upper and lower extremities, with sparing of the palms, soles and face (Fig. 1).

\section{RESULTS}

Additional signs included enamel dysplasia and myopia, but with no systemic findings. Histological examination showed acanthosis and papillomatosis of the epidermis with massive EHK (Fig. 2). Based on the clinical and pathological findings the patient was diagnosed with a systematized epidermolytic epidermal naevus (Ichthyosis hystrix type) and managed and advised accordingly.

\section{DISCUSSION}

Epidermal nevi (EN) are congenital hamartomas derived from ectodermal structures. They follow the pathways of ectodermal development and 


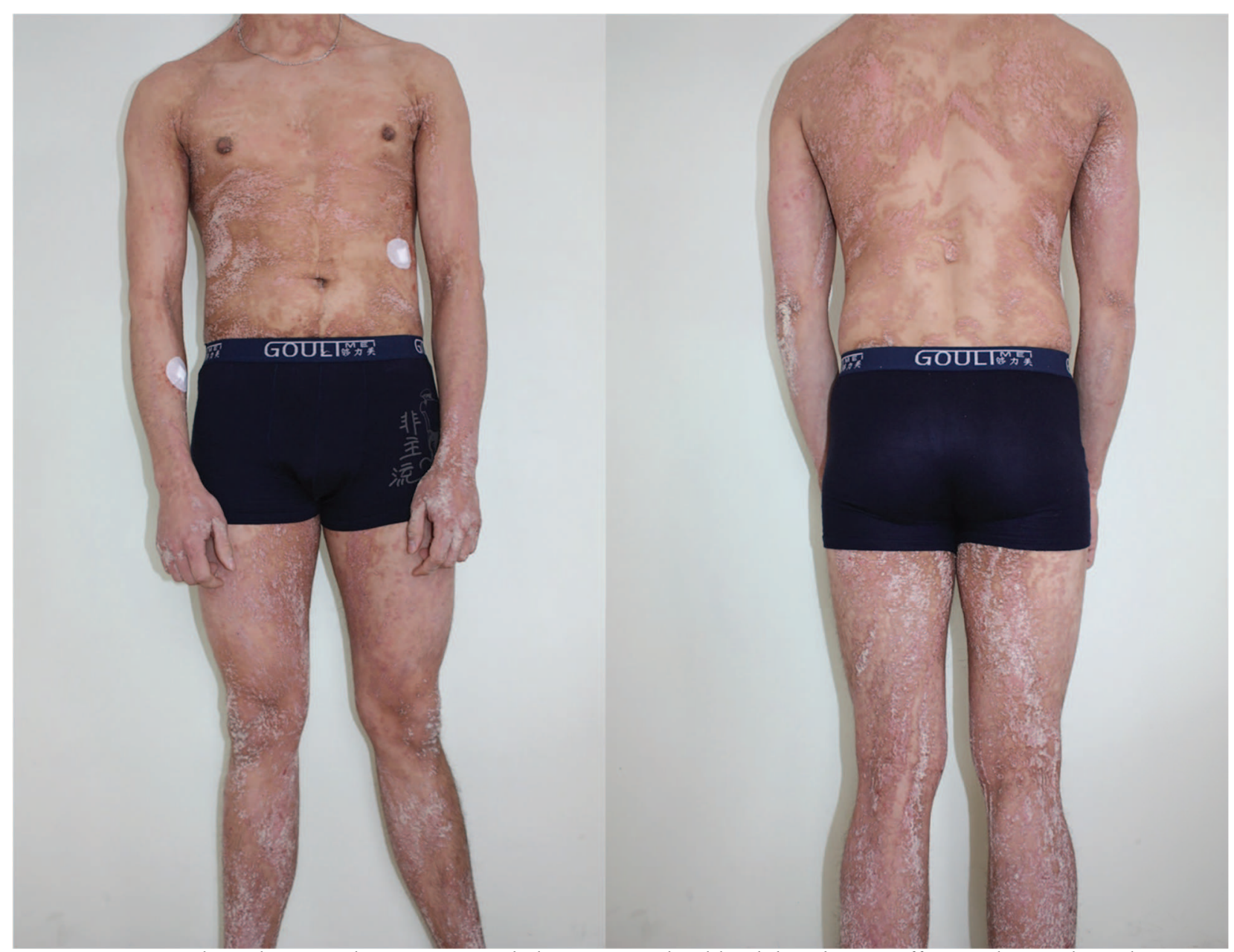

Fig. 1. Extensive hyperkeratotic hyperpigmented plaques in a Blaschkoid distribution affecting the trunk, neck, upper and lower extremities

clinically present along the lines of Blaschko. Bilateral, extensive lesions that cover large areas of the body are defined as systematized epidermal nevi.

The EN with keratinocytic differentiation are also known as verrucous epidermal nevi and are divided into epidermolytic and non-epidermolytic depending on the histological features. The first group is, however, relatively uncommon as EHK is present in only about $5 \%$ of all EN $(1,2)$. Although not a common finding, EHK is an important prognostic factor for this type of EN. It has recently been confirmed that epidermal nevi with epidermolytic histological features are associated with mutations in the genes encoding keratin $10(3,4)$ and keratin $1(5)$ and represent mosaic forms of BIE. In addition to cutaneous mosaicism parents with epidermolytic epidermal nevi are also likely to have gonadal mosaicism and produce offspring with $\operatorname{BIE}(3,6)$.

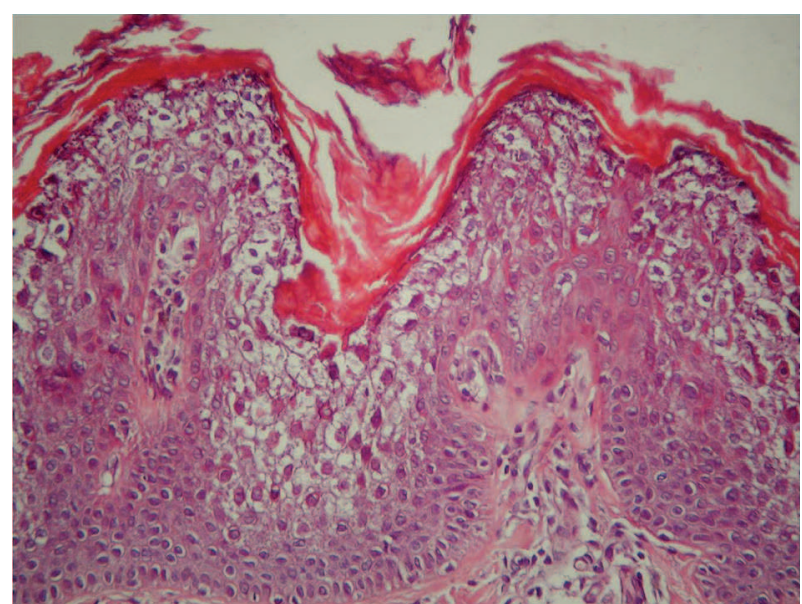

Fig. 2. Histological examination showed acanthosis and papillomatosis of the epidermis with massive EHK

Icthyosis hystrix (IH) is a term that encompasses a heterogenous group of disorders. In the literature 
Systematized epidermolytic epidermal nevus (Ichthyosis Hystrix)

it is sometimes used interchangeably with extensive epidermal nevus with marked hyperkeratosis. Clinical presentation varies from palmoplantar keratoderma to generalized involvement with verrucous or porcupine-like (hystrix) hyperkeratosis. Regardless of the clinical similarity to BIE, blistering in early age does not occur. The Blaschkoid distribution is considered by some authors as distinctive between $\mathrm{IH}$ and EN, being characteristic of the former (7). Nevertheless, similarly to EN, mutations in the genes encoding keratin 1 have also been described in $\mathrm{IH}(8,9)$. The similar molecular defect might explain the clinical overlap and the resulting difficulty in precise differentiation between these two conditions.

\section{CONCLUSION}

A diagnosis of epidermal nevus syndrome should be thought in patients with extensive epidermal nevi and or systemic abnormalities. A thorough muco-cutaneous, neurologic, ophthalmic and orthopedic examination is necessary with specific investigations depending on the involved system.

\section{REFERENCES}

1. Su WP. Histopathologic varieties of epidermal nevus. A study of 160 cases. Am J Dermatopathol 1982; 4: 161-70.

2. Ortiz BM, Masi MR, Da Silva RN, et al. Ictiosis hystrix (nevus epidérmico diseminado) asociado a hiperqueratosis epidermolítica. Rev Esp Patol 2006; 39: 190-192.

3. Paller AS, Syder AJ, Chan Y-M et al. Genetic and clinical mosaicism in a type of epidermal nevus. $\mathrm{N}$ Engl J Med 1994; 331: 1408-15.

4. Moss C, Jones DO, Blight A, Bowden PE. Birthmark due to cutaneous mosaicism for keratin 10 mutation. Lancet 1995; 345: 596.

5. Tsubota A, Akiyama M, Sakai K et al. Keratin 1 gene mutation detected in epidermal nevus with epidermolytic hyperkeratosis. J Invest Dermatol 2007; 127: 1371-4.

6. Nomura K, Umeki K, Hatayama I, Kuronuma T. Phenotypic heterogeneity in bullous congenital ichthyosiform erythroderma: possible somatic mosaicism for keratin gene mutation in the mildly affected mother of the proband. Arch Dermatol 2001; 137: 1192-5.
7. Sybert VP. Ichthyosis Hystrix. In: Genetic Skin Disorders. New York : Oxford University Press, 2010: 19-22.

8. Sprecher E, Ishida-Yamamoto A, Becker OM, et al. Evidence for novel functions of the keratin tail emerging from a mutation causing ichthyosis hystrix. J Invest Dermatol 2001; 116: 511-9.

9. Ishida-Yamamoto, A., Richard, G., Takahashi, H., Iizuka, H. In vivo studies of mutant keratin 1 in ichthyosis hystrix Curth-Macklin. J. Invest. Derm 2003; 120: 498-500. 